\title{
Machinability of Al 6061 deposited with Cold Spray additive manufacturing
}

\author{
Barry Aldwell ${ }^{1}$, , Elaine Kelly², Ronan Wall ${ }^{2}$, Andrea Amaldi ${ }^{3}$, Garret E. O’Donnell ${ }^{1}$, Rocco Lupoi ${ }^{1}$
}

${ }^{1}$ Department of Mechanical and Manufacturing Engineering, Parsons Building, Trinity College Dublin, Dublin 2, Ireland.

2 Moog Dublin, 15 Northwest Business Park, Ballycoolin, Dublin 15, Ireland

${ }^{3}$ European Space Research and Technology Centre (ESTEC), European Space Agency, Keplerlaan 1, 2201 AZ Noordwijk,

The Netherlands

Abstract: Additive manufacturing techniques such as cold spray are translating from research labs into more main stream high end production systems. Similar to many additive processes, finishing still depends on removal processes. This research presents the results from investigations into aspects of the machinability of Aluminium 6061 tubes manufactured with Cold Spray. Through the analysis of cutting forces and observations on chip formation and surface morphology, the effect of cutting speed, feed rate and heat treatment were quantified, for both cold sprayed and bulk Aluminium 6061. High speed video of chip formation shows changes in chip form for varying material and heat treatment, which is supported by the force data and quantitative imaging of the machined surface. The results shown in this paper demonstrate that parameters involved in cold spray directly impacts on machinability, and therefore has implications for machining parameters and strategy.

Keywords: Cold Spray, Additive Manufacturing, Machining, Cutting, Near-Net-Shape

\section{Introduction}

Cold Spray has been used as additive manufacturing technology (Ref 1,2), with most interest being for repair (Ref 3-5); including novel applications such for as the manufacture of anti-bacterial coatings(Ref 6); material removal processes are typically necessary to achieve the desired geometry and surface finish. While the machining of cold sprayed materials has been initially explored (Ref 7), no work has been done on chip formation when machining cold sprayed materials.

Cold Spray is a deposition process where a powder, typically spherical, is injected into a high pressure (1-4 $\mathrm{MPa}$ ) gas stream, which then travels through a converging-diverging nozzle and accelerates the 
powder to supersonic speeds. The powder then impacts on a substrate and deforms, forming a coating through deformation of the individual particles, with no phase change involved.

The choice of carrier gas is of particular interest in cold spray, as its achievable speed directly affects the particle velocity. Common carrier gasses include nitrogen and helium, with helium having a sonic speed of $1007 \mathrm{~m} / \mathrm{s}$, compared to $349 \mathrm{~m} / \mathrm{s}$ for nitrogen in ambient conditions. Thus, by using helium it is possible to achieve higher particle velocities, however at a much increased cost. In nitrogen systems gas pre-heating is often applied to decrease the density of the gas, thus increasing the sonic speed, and hence the achievable exit velocity. Increasing the particle velocity for ductile materials would be expected to increase particle deformation and bonding, and decrease the porosity of the deposited material. It should be noted that when spraying low ductility materials fracture may be observed rather than deformation (Ref 8).

Cold sprayed materials reported in the literature commonly display lower stiffness and more brittle failure modes than bulk material (Ref 9), though heat treatment processes can be used to improve ductility (Ref 10). The bonds between individual particles are often mechanical in nature (Ref 11), being caused by intermixing of particles during deposition, or metallurgical in nature, due to adiabatic shearing at high strain rates removing any oxide layers or similar barriers, and allowing adhesion between particles (Ref 12).

The main factors which affect machinability in fully dense materials include tool life, cutting forces, surface finish, and chip formation mechanism (Ref 13). When machining a porous material the effect of the porosity on the machining process must be incorporated into any analysis, including the effect of the porosity on the stiffness of the material (Ref 14). Porous materials typically show interrupted cutting with small chips (Ref 15), as illustrated in Figure 1. The interrupted cutting is due to the cutting edge entering and exiting pockets of porosity, while the small, discontinuous chips are commonly a result of the porosity causing stress concentrations which lead to elastic failure of the material, rather than the plastic deformation seen when forming a chip. The porosity may also be smeared and densified by the cutting edge, leaving a surface which appears less porous than the bulk material (Ref 16,17). In a cold sprayed material the interparticle bonds are a possible source of elastic failure during machining, which will prevent a chip from being formed and lead to a poor surface finish. 


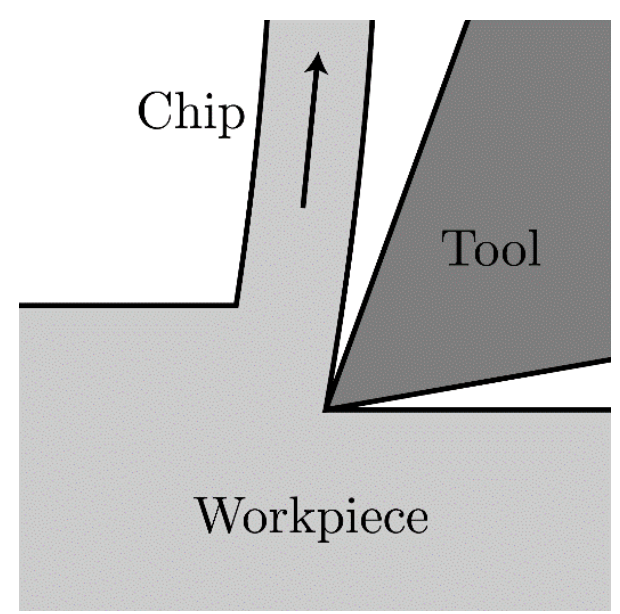

a) Chip formation for fully dense bulk material.

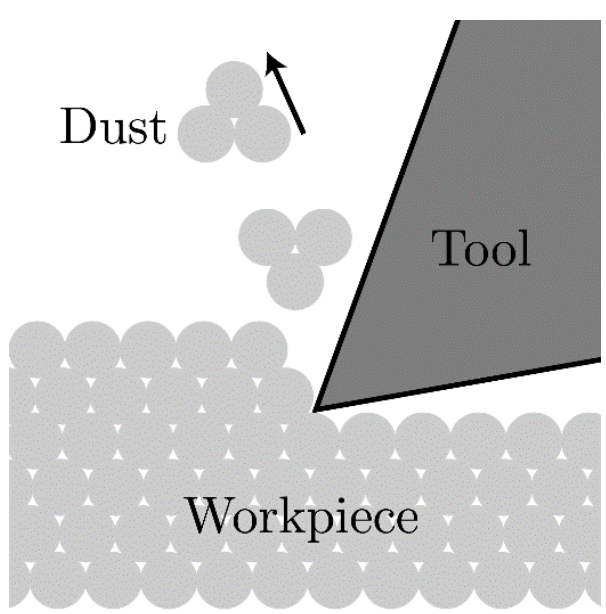

b) Simplified model of cutting of material formed from undeformed spherical particles with weak interparticle bonds. Adapted from (Ref 16).

Figure 1: Schematic of material removal for bulk and porous materials.

When machining materials which have some porosity, such as cast materials, variations in the cutting force are often observed due to the non-homogeneous nature of the material, and the discontinuous nature of the cut as the cutting tool enters and exits pockets of porosity (Ref 18). Parts produced using powder metallurgy show reductions in cutting force when compared to bulk material, due to the porosity between particles (Ref 16,19). Machining of parts produced using EBM (Ref 20) has shown modified chip formation in porous components, along with higher tool wear due to a more abrasive microstructure. Components manufactured using additive processes involving a phase change often show higher machining forces, as has been reported for laser sintering (Ref 21), Laser Engineered Net Shaping (LENS), and Wire Arc Additive Manufacturing (WAAM) (Ref 22).

While there has been a shift towards an increased use of composites in commercial airliners, aluminium alloys remain as crucial materials for aeronautical, aerospace, and defence applications, with the Boeing 787 consisting of $70 \%$ aluminium alloys by weight (Ref 23 ). Additive manufacturing of these components has seen some research, through processes such as Selective Laser Melting (SLM) (Ref 24), Selective Laser Sintering (SLS), and Laser Engineered Net Shaping (LENS) (Ref 25). It should be noted that the maximum relative density achieved in Aluminium 6061 by SLM was 89.5\%.The density and microstructure delivered by an additive process will likely have a direct effect on the mechanical properties of any components manufactured. This will be of concern in aerospace applications, where aluminium alloy components are used due to their strength, ductility (Ref 26), and resistance to fatigue failure (Ref 27). 
Many of these additive processes also rely upon the use of a controlled environment to prevent oxidation during phase changes, and to control cooling rates to deliver the desired microstructure. This limits the size of the components which can be created, increases expense, and limits the possibilities for repair of components or additive manufacturing onto existing parts. A cold spray process which could achieve high relative density without any phase change could potentially allow for flexible additive manufacturing of aluminium components for aerospace applications.

This paper will therefore investigate the deposition of Al 6061 with Cold Spray, followed by the application of material removal processes. Cutting forces and chip formation mechanisms are measured and reported using a variety of spray parameters in order to provide useful insights into the machinability of cold sprayed deposits. 


\section{Experimental setup}

\subsection{Cold Spray processing}

Cold sprayed samples were manufactured in the TCD Cold Spray laboratory, using Aluminium 6061-T0 powder (spherical shape, 20-63 $\mu$ m diameter, purchased from LPW Technology), with an Al 6061-T6 tube as a substrate. Samples were sprayed using both nitrogen $\left(\mathrm{N}_{2}\right)$ and helium $(\mathrm{He})$ as carrier gasses to assess the effect of particle velocity, i.e. lower with nitrogen and higher with helium. Two samples were manufactured using each carrier gas. A nozzle traverse speed of $200 \mathrm{~mm} / \mathrm{s}$ was used, using a nozzle standoff distance of $40 \mathrm{~mm}$. The samples sprayed using nitrogen used gas heating to $400^{\circ} \mathrm{C}$ with a particles pre-heater section and a gas pressure of $3 \mathrm{MPa}$, with a converging-diverging nozzle of overall length $180 \mathrm{~mm}$, with throat diameter of $2 \mathrm{~mm}$ and exit diameter of $6 \mathrm{~mm}$, The samples sprayed using helium used gas heating to $200^{\circ} \mathrm{C}$ and a gas pressure of $2 \mathrm{MPa}$, with an in-line particle preheater of length $110 \mathrm{~mm}$ and a converging-diverging nozzle of overall length $35 \mathrm{~mm}$, with throat diameter of $2.27 \mathrm{~mm}$ and exit diameter of $3.8 \mathrm{~mm}$. Typical particle velocities at the standoff distance are $802 \mathrm{~m} / \mathrm{s}$ for the long nozzle with helium, and $540 \mathrm{~m} / \mathrm{s}$ for the short nozzle with nitrogen. The deposition of this $\mathrm{Al}$ alloy using $\mathrm{N}_{2}$ as carrier gas is difficult due to the low achievable particle impact velocity; this is the reason of why a particle pre-heater section was used. Pre-heated particle are thermally softened and will deposit at lower speed thresholds.

\subsection{Machining operations}

After being manufactured, the cold sprayed samples were prepared for cutting forces measurements experiments by turning down the outside diameter and boring out the inside diameter to achieve a wall thickness of $2.1 \mathrm{~mm}$, to match the wall thickness of the tube used as a substrate. Prior to machining one $\mathrm{N}_{2}$ sprayed sample and one He sprayed sample were annealed to improve ductility (Ref 28) (heated to $410^{\circ} \mathrm{C}$ for 3 hours, then cooled at $40^{\circ} \mathrm{C}$ per hour to $260^{\circ} \mathrm{C}$, followed by cooling in air (Ref 29)), along with a section of the substrate tubing. Samples of T6 and annealed tube were also machined to provide data on the cutting forces for bulk Aluminium 6061. A sample prepared for machining tests is shown in Figure 2. 


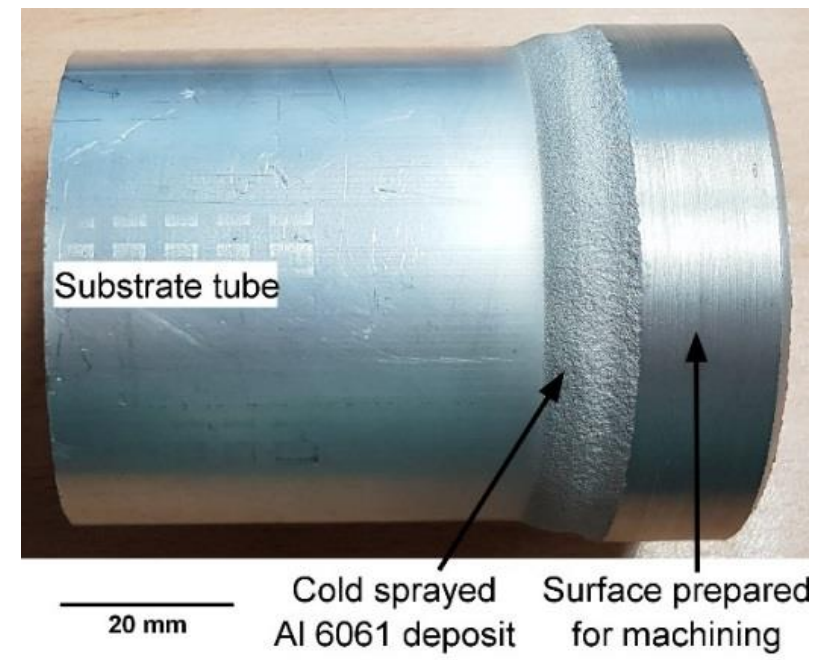

Figure 2: Sample prepared for machining test

Machining experiments were carried out in an Okuma LT15-M lathe, using a Kistler 9263 dynamometer to acquire cutting force data. Machining was carried out using WNT TCGT 110202-AL CWK15 inserts, oriented to cause orthogonal cutting of the tube workpieces. Video of chip formation was acquired using a HotShot $1700 \mathrm{cc}$ high speed camera, and chips were collected after machining operations. Two levels each of cutting speed and feed rate were used. The full design of experiments is shown in Table 1.

Table 1: Design of experiments

\begin{tabular}{lll}
\hline Factor & Number of levels & Levels \\
\hline Material & 3 & Bulk, cold sprayed with $\mathrm{N}_{2}$, cold sprayed with \\
& & $\mathrm{He}$ \\
Heat treatment & 2 & None, Annealed \\
Cutting speed & 2 & $200,400 \mathrm{~m} / \mathrm{min}$ \\
Feed rate & 2 & $0.05,0.1 \mathrm{~mm} / \mathrm{revolution}$ \\
\end{tabular}

After machining operations, the average of the steady-state value for cutting force and thrust force for each operation is extracted from the force data, and the results used in an Analysis of Variance (ANOVA) to establish the parameters of interest in machining. 
The machined surfaces were inspected using an ADE Omniscan MicroXam white light interferometer. This instrument provides surface topography data, along with a $S_{a}$ value. $S_{a}$ is a surface roughness parameter, measuring the arithmetic mean height of a surface. Rings were removed from each of the prepared machining samples using a parting-off tool, and the density of each was measured using a PCE ABZ 200C Archimedes balance tester. Thus, the density was measured on cold sprayed samples that have been previously machined.

\section{Results and discussion}

\subsection{Sample density}

The density values for each sample are shown in Table 2. A two sample T test shows that the differences between the original and annealed density values are not statistically significant for any deposition strategy. The helium sprayed samples have higher density than the nitrogen sprayed samples, due to the higher particle velocity resulting from by the use of helium as an accelerating gas. Both deposits are therefore not fully dense and show a level of porosity.

Table 2: Measured density values for bulk and cold sprayed deposits

\begin{tabular}{lll}
\hline & Original & Annealed \\
& & \\
\hline Bulk & $2.7024 \pm 0.0043 \mathrm{~g} / \mathrm{cm} 3$ & $2.7022 \pm 0.0045 \mathrm{~g} / \mathrm{cm} 3$ \\
$\mathrm{~N} 2$ & $2.479 \pm 0.0105 \mathrm{~g} / \mathrm{cm} 3$ & $2.4731 \pm 0.015 \mathrm{~g} / \mathrm{cm} 3$ \\
$\mathrm{He}$ & $2.5515 \pm 0.0082 \mathrm{~g} / \mathrm{cm} 3$ & $2.5383 \pm 0.0056 \mathrm{~g} / \mathrm{cm} 3$ \\
\hline
\end{tabular}

The expected theoretical material stiffness for the porosity levels measured, as per the model proposed by Lu, Lu and Xiao (Ref 14), are shown in Table 3. Their model for low porosity levels is shown in equation 1 below:

$$
E=E_{0}(1-2 \phi)\left(1+4 \phi^{2}\right)
$$


Where $\mathrm{E}$ is the stiffness of the porous material, $\mathrm{E}_{0}$ is the stiffness of the same material at full density, and $\phi$ is the porosity. These values show the predicted elastic modulus for the level of porosity measured, as a percentage of the elastic modulus of the fully dense material. If the change in machinability is purely a result of the change in elastic modulus then it would be expected that the ratio of the cutting forces for the cold sprayed part to the bulk part would be similar to the levels predicted here.

Table 3: Expected stiffness levels for levels of porosity shown in Table 2

\begin{tabular}{lll}
\hline & Original & Annealed \\
& & \\
\hline Bulk & $100 \%$ & N/A \\
& & \\
$\mathrm{N}_{2}$ & $85.75 \%$ & $85.42 \%$ \\
$\mathrm{He}$ & $89.94 \%$ & $89.15 \%$ \\
\hline
\end{tabular}

\subsection{Cutting force}

Investigation of the cutting forces was carried out using Analysis of Variance (ANOVA) approach(Ref 30). In this approach each possible combination of factors is investigated (in this case, machined with the material and machining parameters for that level), and a response is measured (in this case, the average value of the steady state cutting force). A statistical test is then carried out to measure the significance of each factor, both as a main effect and as an interaction with the others. Graphically the data can then be analysed through main effects plots similar to Figure 3, and interactions plots similar to Figure 4. No error bars are presented in these graphs as the statistical testing incorporates the analysis of error within the model used. The graphs are instead presented as a comparison of mean values, to show the effect of the factors on the mean values of the response.

A main effects plot for cutting force is shown in Figure 3, with an interactions plot shown in Figure 4. The ANOVA model used has a $\mathrm{R}^{2}$ value of $99.06 \%$. Material $(\mathrm{P}=0.097)$ and cutting speed $(\mathrm{P}=0.065)$ are not statistically significant at the $5 \%$ significance level, while heat treatment $(P=0.028)$ and feed rate $(P=$ 0.042) are statistically significant. 


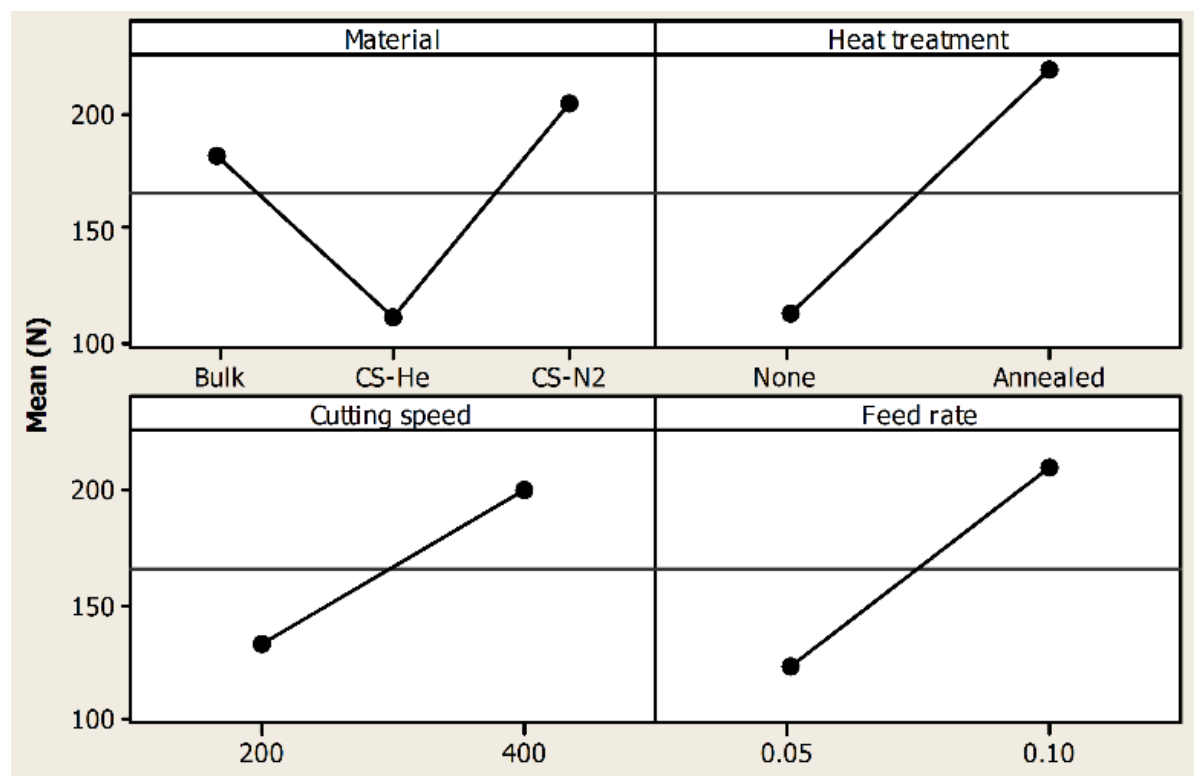

Figure 3: Main effects plot for cutting force

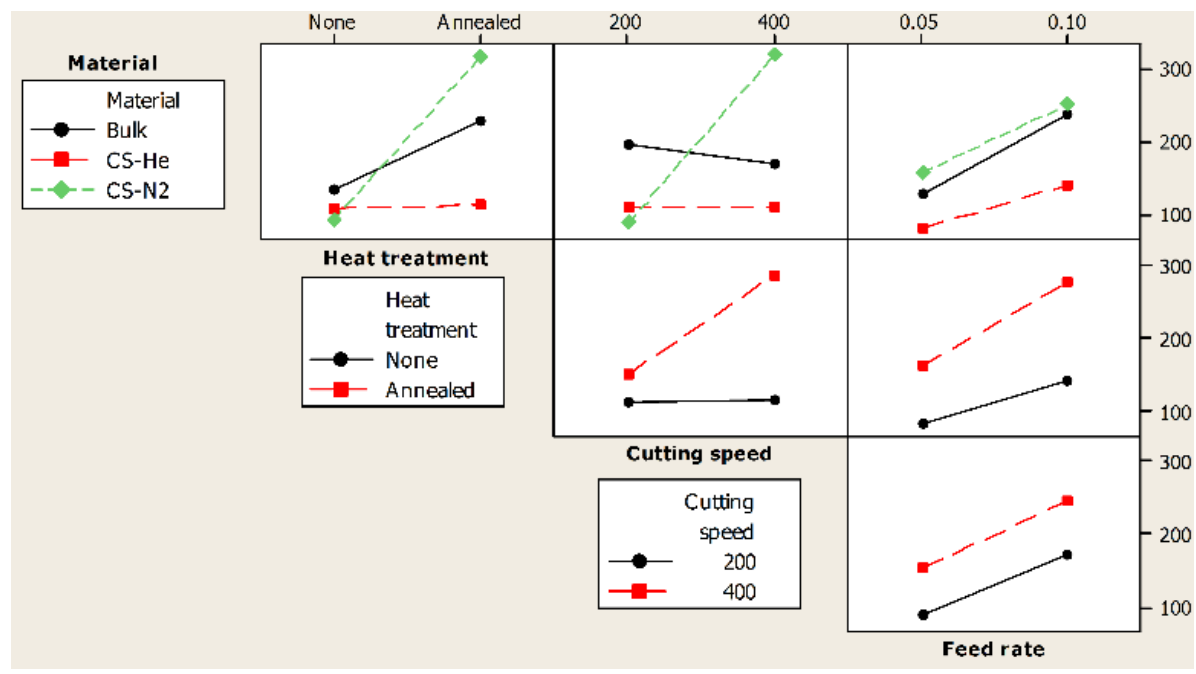

Figure 4: Interactions plot for cutting force

Of the interactions, only material-cutting speed $(\mathrm{P}=0.049)$ is statistically significant. Inspection of the data shows that the annealed samples sprayed using nitrogen show very high values of cutting force (485 $\mathrm{N}$ and $685 \mathrm{~N}$ for the low and high values of feed rate, respectively), when machined at the higher cutting speed.

\subsection{Thrust force}

A main effects plot for thrust force is shown in Figure 5, with an interactions plot shown in Figure 6. The ANOVA model used has a $\mathrm{R}^{2}$ value of $99.92 \%$. The effect of material $(\mathrm{P}=0.004)$ is clear, with samples 
sprayed with nitrogen having much higher thrust forces, with the annealing process having a similar effect for heat treatment $(P=0.003)$. Higher values of cutting speed $(P=0.006)$ and feed rate $(P=0.049)$ also cause higher thrust forces.

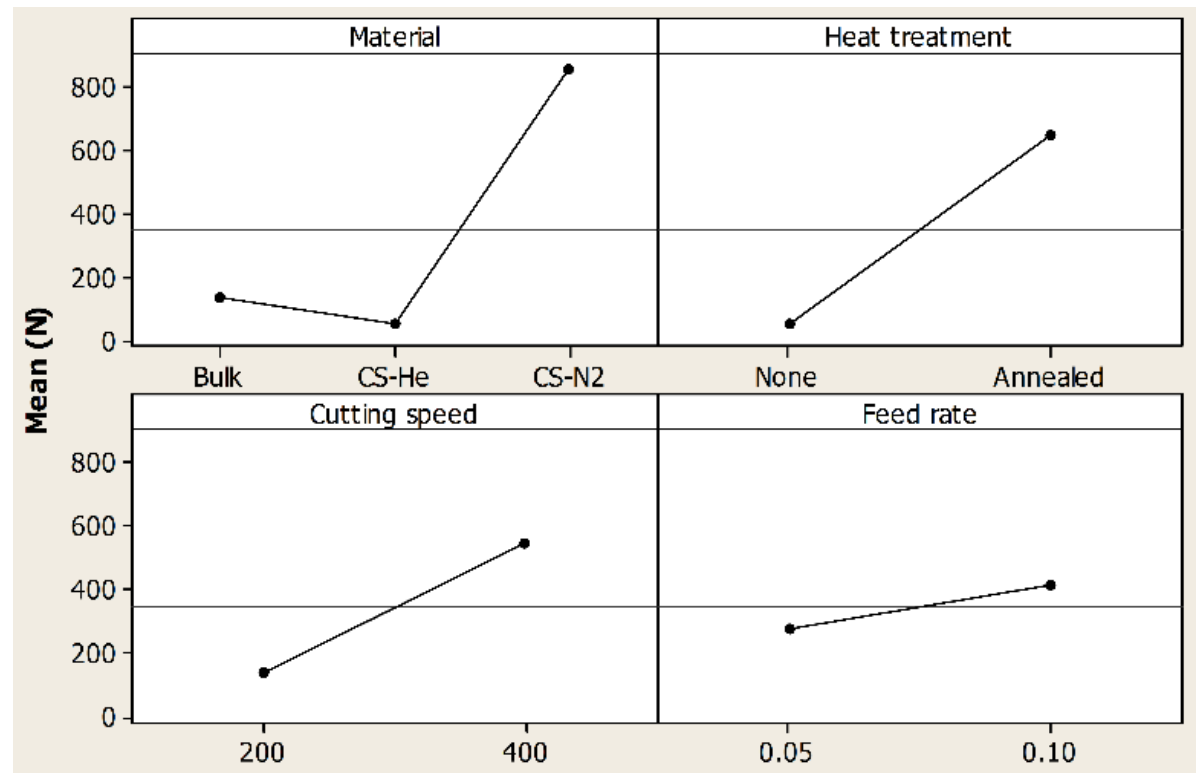

Figure 5: Main effects plot for cutting force

Of the two-way interactions, material-heat treatment $(\mathrm{P}=0.004)$, material-cutting speed $(\mathrm{P}=0.005)$ and heat treatment - cutting speed $(P=0.006)$ are statistically significant. Of the higher order interactions, only material-heat treatment-cutting speed $(\mathrm{P}=0.006)$ is statistically significant. As was observed for cutting speed, annealed samples sprayed using nitrogen and machined at the higher cutting speed show very high values of thrust force $(2829 \mathrm{~N}$ and $3212 \mathrm{~N}$ for the low and high values of feed rate, respectively). This is not observed in the machining of annealed bulk material or helium cold sprayed material. The high forces suggest that there is plowing or smearing occurring rather than chip formation. 


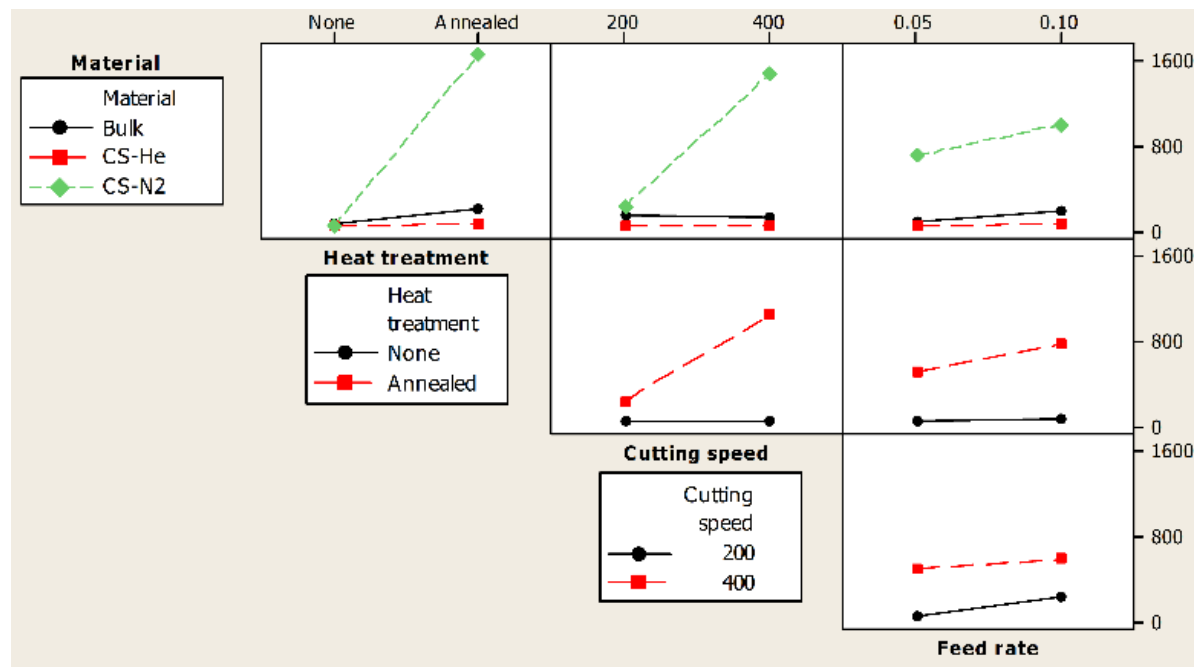

Figure 6: Interactions plot for thrust force

\subsection{Comparison of cutting forces with theoretical stiffness of porous materials}

In order to analyse the effect of porosity on cutting forces it is necessary to express the cutting force and thrust force as a percentage of the force for a fully dense material of similar heat treatment. Table 4 shows these values along with the nominal stiffness levels. If the changes in machining forces were purely due to the porous material being less stiff than bulk then the force ratios should be close to the theoretical stiffness values predicted using the density for each sample (Ref 14). It can be seen that the samples which were not heat treated show forces lower than that predicted by the stiffness equation for porous materials. The annealed samples show higher forces, with the helium sprayed sample showing forces close to the levels predicted, and the nitrogen sprayed sample showing forces far higher, despite both sprayed samples having densities between $91.5 \%$ and $95 \%$. This indicates that the porosity alone may not be the only relevant predictor of machinability, particularly if a heat treatment process is to be used. The annealing process, which would be expected to relieve residual stresses and improve bond strength, has also changed the machinability of the material for the nitrogen sprayed sample. The lower particle deformation for the nitrogen sprayed samples may be causing the material to machine in a similar manner to a sintered material, with individual particles or small groups of particles fracturing being removed by fracture along particle boundaries, rather than a shearing action creating a chip. 


\begin{tabular}{|c|c|c|c|c|c|}
\hline & Heat treatment & Density & $\begin{array}{l}\text { Theoretical stiffness } \\
\text { (Ref 14) }\end{array}$ & Cutting force ratio & Thrust force ratio \\
\hline Bulk & None & $100 \%$ & $100 \%$ & $100 \%$ & $100 \%$ \\
\hline \multirow{3}{*}{$\mathrm{N}_{2}$} & None & $91.73 \%$ & $85.75 \%$ & $68.3 \%$ & $69.2 \%$ \\
\hline & & & & & \\
\hline & Annealed & $91.51 \%$ & $85.42 \%$ & $241 \%$ & $2630 \%$ \\
\hline \multirow{3}{*}{$\mathrm{He}$} & None & $94.97 \%$ & $89.94 \%$ & $78.9 \%$ & $78.6 \%$ \\
\hline & & & & & \\
\hline & Annealed & $93.93 \%$ & $89.15 \%$ & $83.4 \%$ & $89.7 \%$ \\
\hline
\end{tabular}

Figure 7 shows chemically etched cross sections of cold sprayed Al-6061 samples using similar parameters to those presented in this study, with both nitrogen and helium gases. The helium sprayed sample in Figure 7 (b) shows larger deformation of individual particles in the coating (the original feedstock is of spherical shape), which will cause significant work hardening and microstructure refinement due to the high strain rates involved. In Cold Spray, particle impact velocities were in the range of $500-800 \mathrm{~m} / \mathrm{s}$, giving strain rates in the $10^{6}-10^{9} / \mathrm{s}$ range. Particle plastic deformation in the nitrogen made sample, shown in Figure 7 (a), is on the other hand limited due to the lower particle speed. The use of a pre-heating particles section (as described in section 2.1) allows the material to deposit and stick together, but not in a well consolidated manner as opposed to the helium case.

While the samples in Figure 7 are of similar densities, they are unlikely to have similar mechanical properties, as the interparticle bonding will be far stronger and over larger areas in the helium sprayed sample, due to the higher levels of deformation and mechanical interlocking associated with increased particle velocity, and stronger metallurgical bonds due to increased shearing from the higher particle velocity. Any post heat treatment processes will also have different effects, as the helium sprayed sample will have grain refinement due to the large levels of cold work experienced by the particles, while the original microstructure of the nitrogen sprayed sample will not experience high levels of grain refinement. Grain refinement has in the past been shown to improve machinability of Aluminium 6061 
(Ref 31); this can demonstrate that despite measuring similar densities in the $\mathrm{N}_{2}$ and He samples, their machining behaviour can be very different and particularly in an annealed state.

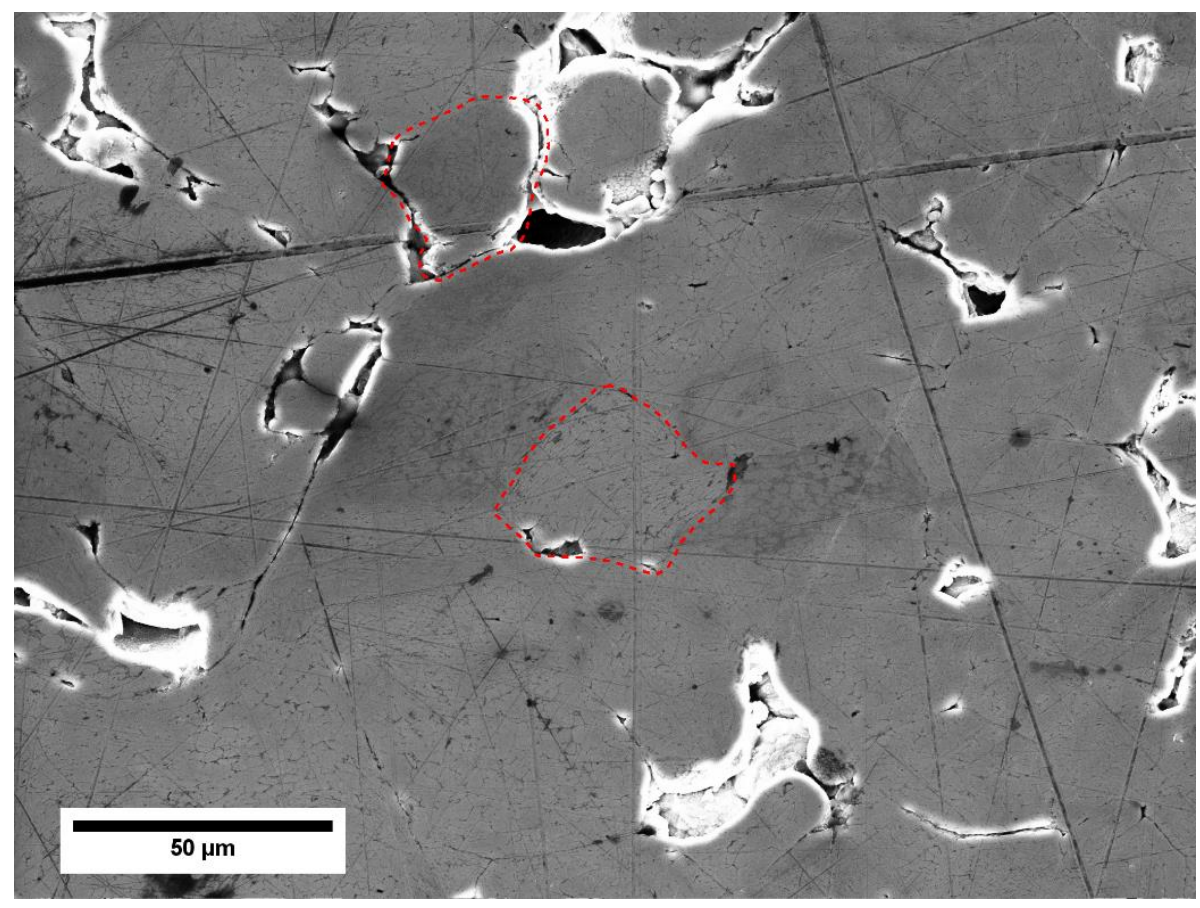

a) $\mathrm{N}_{2}$ sprayed

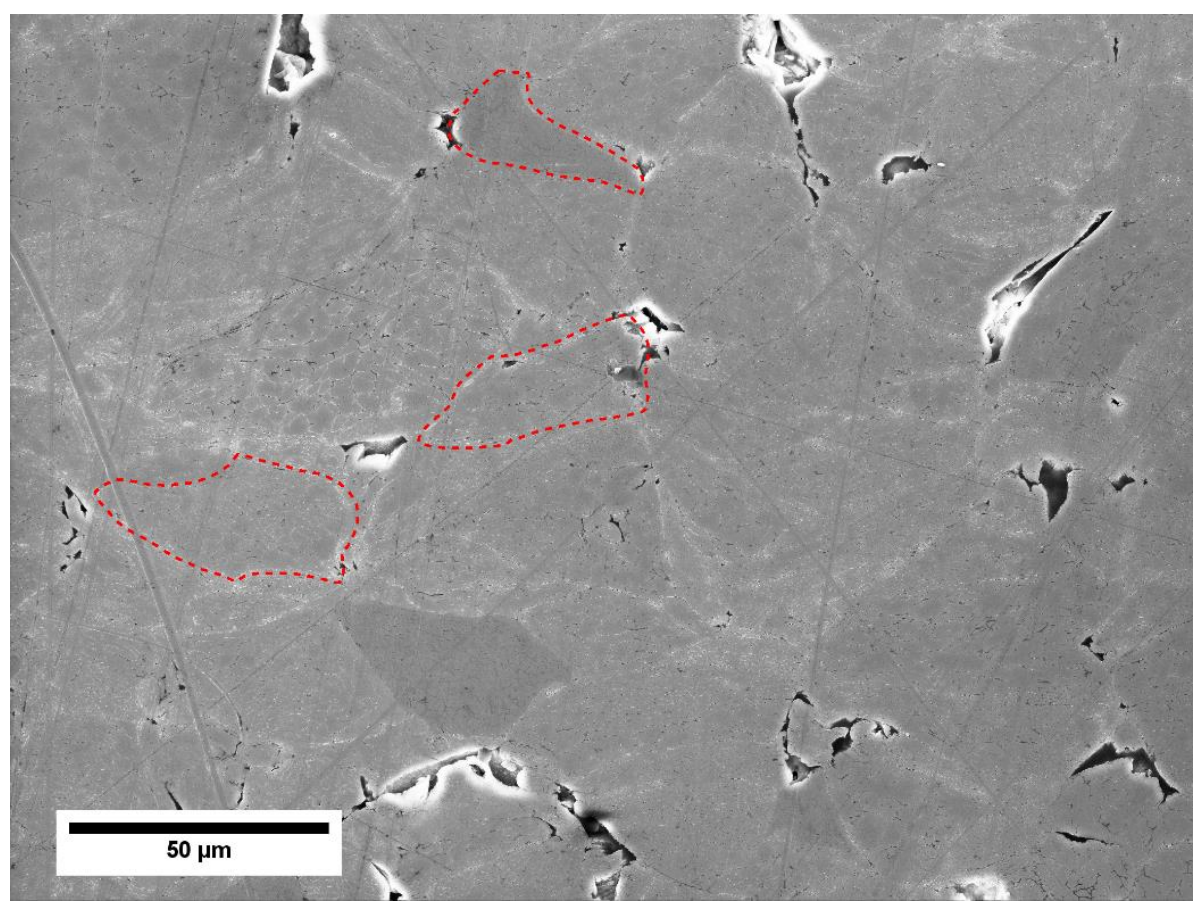

b) He sprayed

Figure 7: Etched cross sections, showing little particle deformation for nitrogen sprayed samples when compared to helium sprayed samples 
Table 5 shows the microhardness for each material. It can be seen that the as sprayed deposits have hardness levels below that of the T6 bulk material, but exceeding that of the annealed bulk material. The high variability of the as sprayed samples is a result of the porous and brittle nature of the deposit, with the annealed samples showing a reduction in hardness due to material softening, but also a reduction in the variation of the results due to improvements in the interparticle bonds. Both the as sprayed and annealed samples sprayed using helium show higher hardness levels when compared to the equivalent nitrogen sprayed sample, due to the higher density of the material, and higher particle deformation during spraying.

Table 5: Rockwell type C microhardness of each material

\begin{tabular}{lll}
\hline & Original & Annealed \\
& & \\
\hline Bulk & $111 \pm 1.58$ & $44.88 \pm 1.73$ \\
$\mathrm{~N}_{2}$ & $55.18 \pm 7.63$ & $43.74 \pm 2.07$ \\
& & \\
$\mathrm{He}$ & $73.8 \pm 7.62$ & $54.18 \pm 1.88$
\end{tabular}

\subsection{Chip formation}

Images of chip formation during machining are shown in Figure 8. The bulk materials show continuous chip formation, with the annealed material showing a much thicker chip with large shear intervals due to the material being softer after heat treatment. The samples sprayed using nitrogen show very small discontinuous chips and dust-like being formed during machining, which is consistent with the behaviour expected from a porous, brittle material. The samples sprayed using helium form longer, but still discontinuous chips. The sample sprayed with helium which has been heat treated displays a thick discontinuous chip with large shear intervals, similar to that seen for bulk annealed material. This shows that despite the porous nature of the material, similar chip formation mechanisms are taking place for the bulk material as for the helium sprayed samples. High speed observations in relation to chip formation therefore agree with the cutting force findings reported in Table 4. 


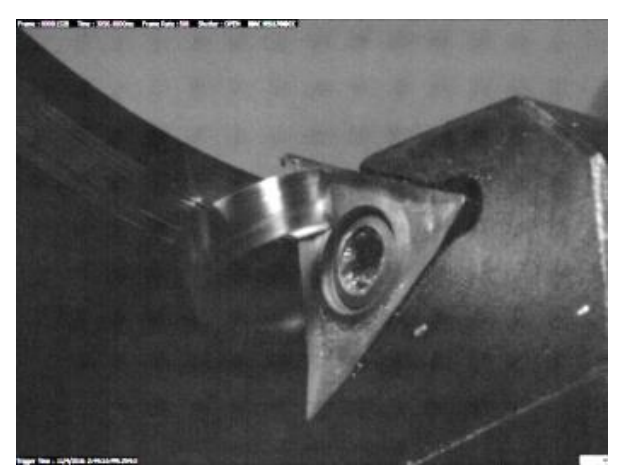

a) Bulk, no heat treatment. Continuous chip formed

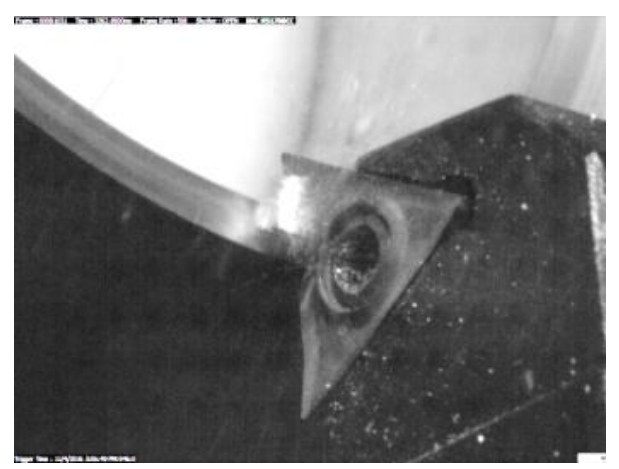

c) $\mathrm{N}_{2}$ cold sprayed, no heat treatment. Very small chip formed

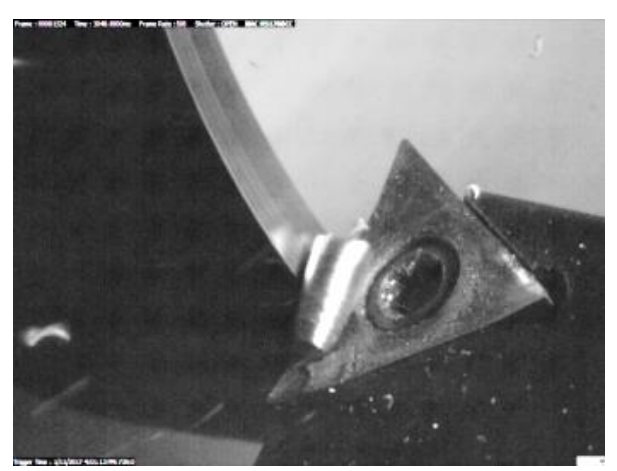

e) He cold sprayed, no heat treatment. Discontinuous curly chip formed

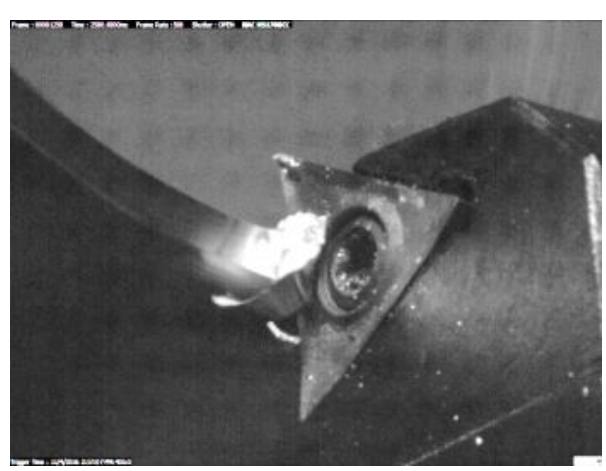

b) Bulk, annealed. Thick continuous chip formed

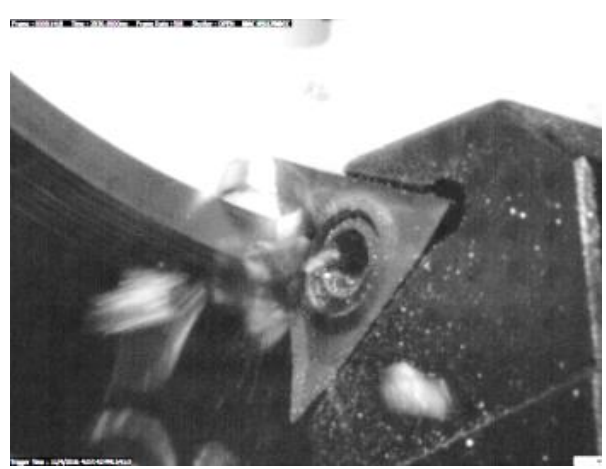

d) $\mathrm{N}_{2}$ cold sprayed, annealed. Dust and small chip fragments formed

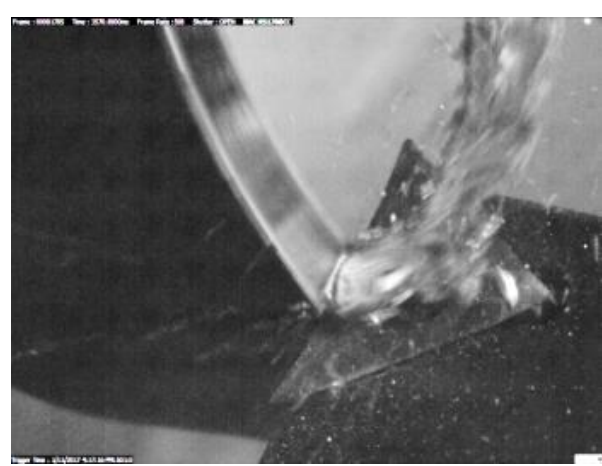

f) He cold sprayed, annealed. Thick discontinuous chip formed

Figure 8: Chip formation mechanisms observed during machining 
Maps of the machined surfaces are shown in Figure 9. The bulk sample shows clear machining marks, reflecting the profile of the tool used. The samples sprayed using nitrogen show no machining marks, showing instead large smearing marks and higher values of $S_{a}$ than the bulk sample. This smearing would indicate that the material is not being removed in a cutting action, but is instead failing at particle boundaries and coming off as small clumps of particles. The annealed sample shows less smearing and a lower value of $S_{a}$, indicating an improvement in interparticle bonding, but not enough to cause a transition to a defined cutting process.

The machined surfaces of the samples sprayed using helium show machining marks, though the assprayed sample shows extreme smearing towards the edges of the cut, indicating a combination of cutting and smearing is occurring. This smearing at the edges also increases the overall value of $\mathrm{S}_{\mathrm{a}}$ for this sample. The annealed sample shows no evidence of smearing, with clear machining marks, and a lower value of $S_{a}$ than seen in the bulk sample. This lower than bulk value may be a result of the porosity in the material allowing for some surface smearing to occur during cutting, which would lead to a smoother surface. 


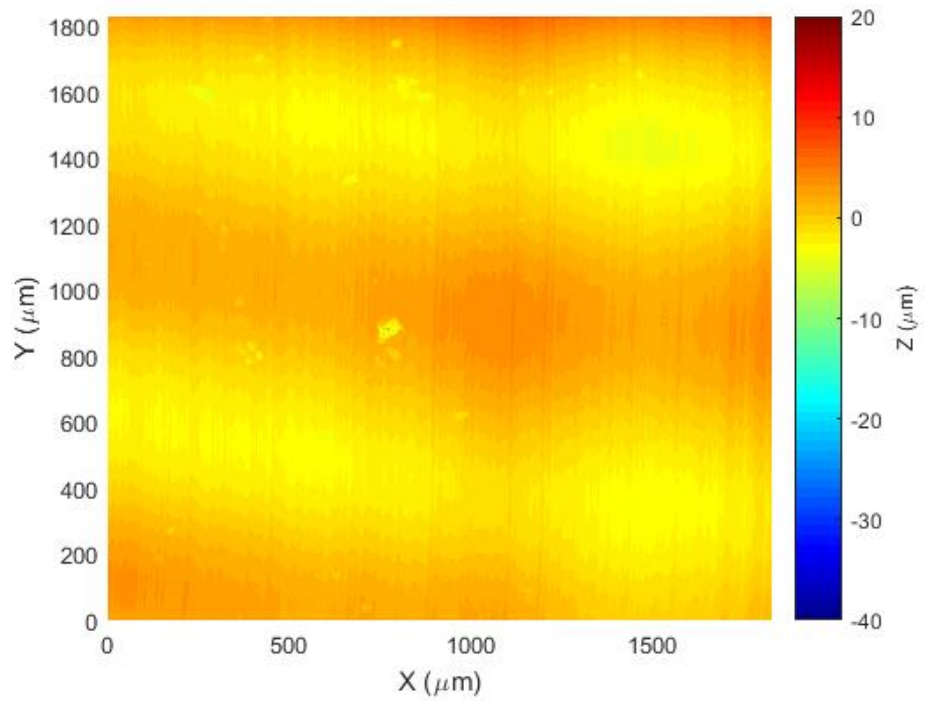

a) Bulk Aluminium 6061-T6. Machining marks clearly visible. $S_{a}=1.662 \mu \mathrm{m}$.

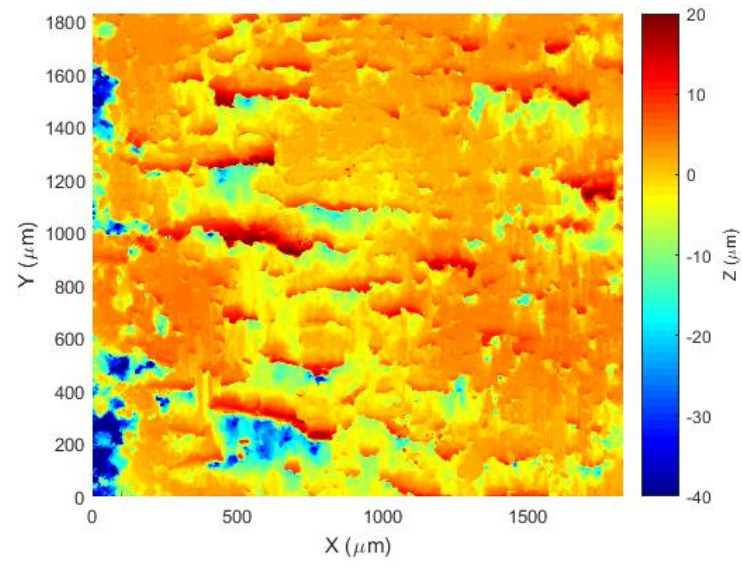

b) N2 cold sprayed, as-sprayed. Heavy smearing evident. $\mathrm{S}_{\mathrm{a}}=4.386 \mu \mathrm{m}$.

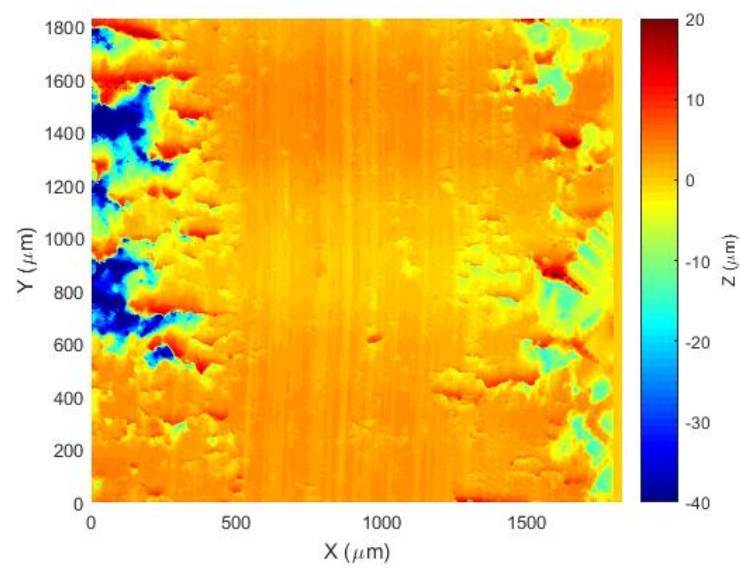

d) He cold sprayed, as-sprayed. Some smearing evident at the edges of the cut, with machining marks visible in the middle of the cut. $S_{a}=3.814 \mu \mathrm{m}$.

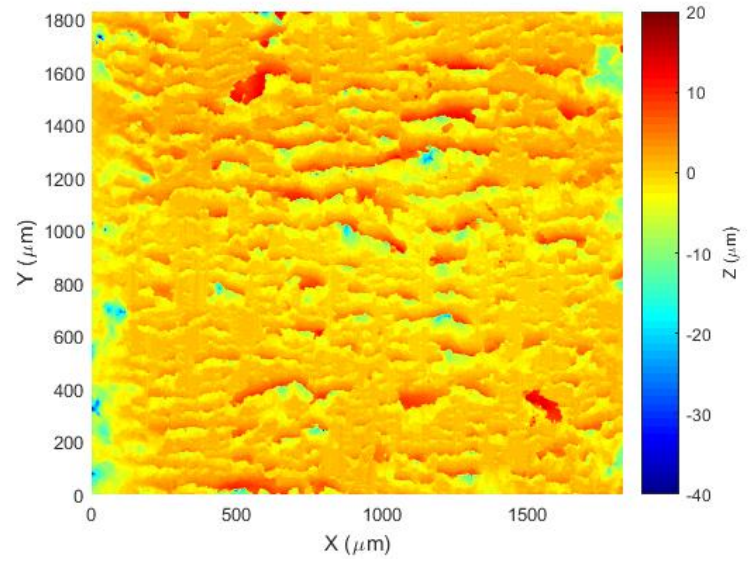

c) N2 cold sprayed, annealed. Some smearing evident. $S_{a}$ $=2.18 \mu \mathrm{m}$.

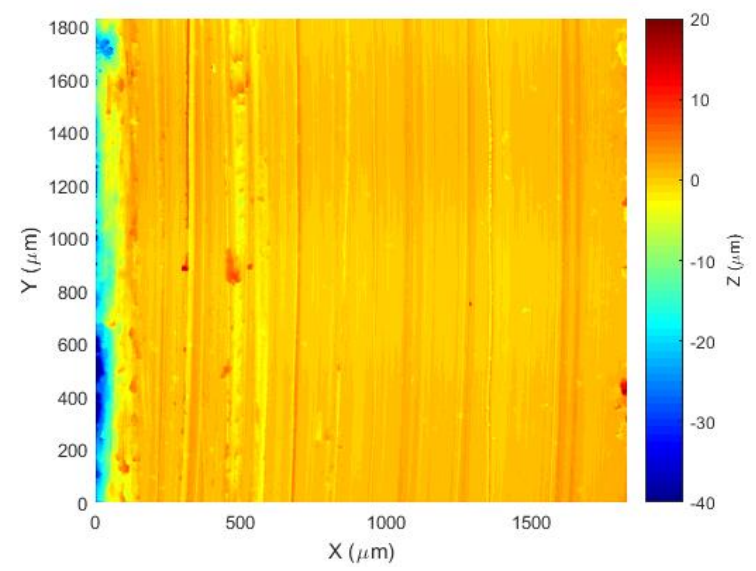

e) He cold sprayed, annealed. Little to no smearing, with machining marks evident. $\mathrm{S}_{\mathrm{a}}=1.378 \mu \mathrm{m}$.

Figure 9: White light interferometer maps of machined surfaces. Direction of cut is top to bottom on all maps. 
Cross sections of machined surfaces are shown in Figure 10. It can be seen that the nitrogen sprayed samples show surface porosity and indications of fracture along particle boundaries, while the helium sprayed samples show smooth machined surfaces, with some densification evident.

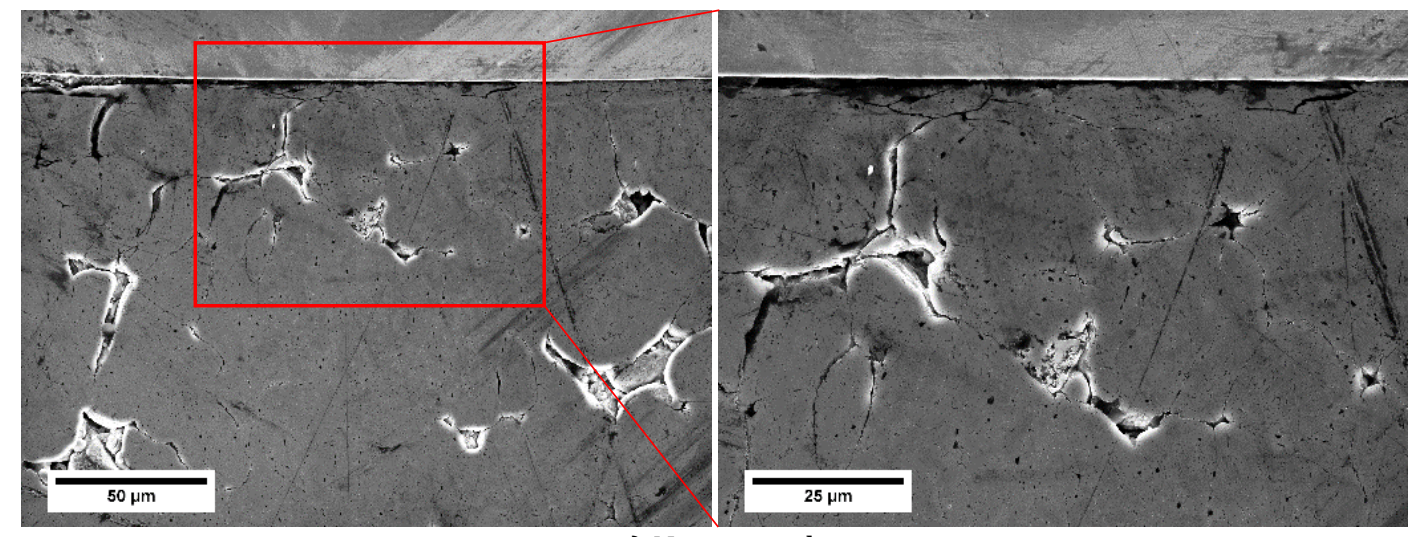

a) $\mathrm{N}_{2}$ sprayed

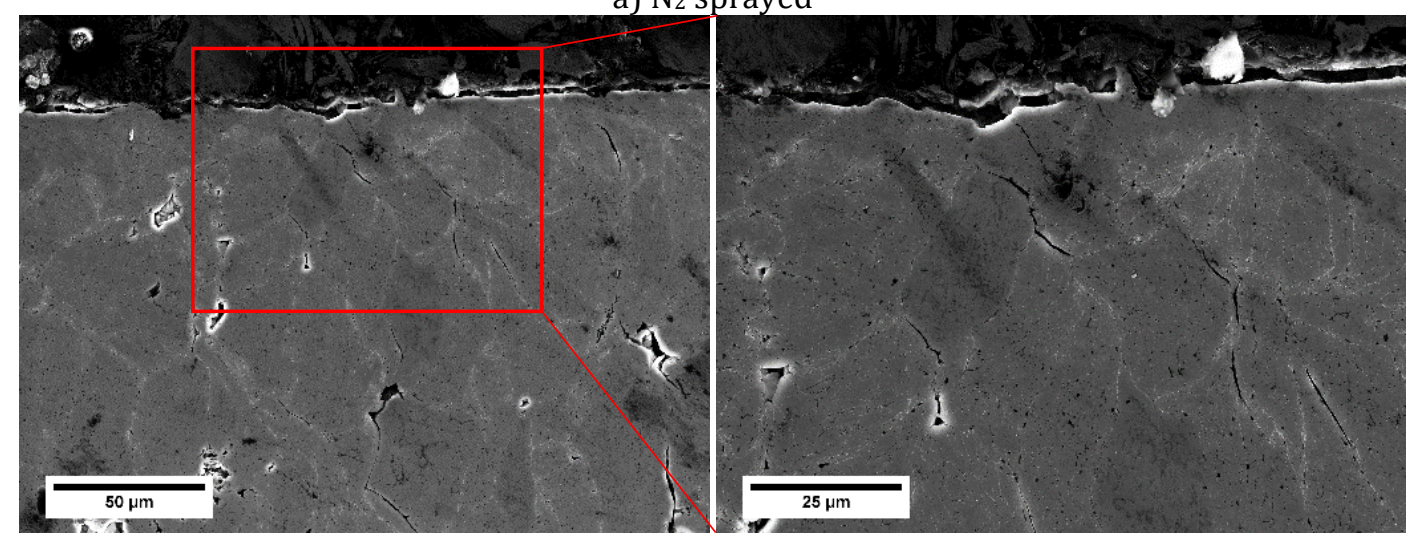

b) He sprayed

Figure 10: Cross sections of machined surfaces. The machined surface is at the top of each image.

\section{Conclusions}

Cold Spray is an emerging process and already being used in the additive field, and is attracting the interest of industry (especially aerospace). In the field the process sits within the near-net-shape window; it therefore needs post-operations so as to achieve the desired shapes. In response to that, an investigation into the machinability of cold sprayed Aluminium 6061 has been carried out and presented in this work.

Samples cold sprayed using nitrogen as a carrier gas with a particle pre-heater showed density of approximately $91-92 \%$ that of the bulk material, with little particle deformation evident within the deposit. Annealing of this material caused a deterioration of the machinability, with similar behaviour to a sintered material. Samples cold sprayed using helium as a carrier gas showed density of approximately 94-95\%, but with much higher particle deformation in the deposit. As a result of this higher particle deformation, the annealing process caused improvements in microstructure and interparticle bonding, with similar machining behaviour and workpiece surface finish to that observed when machining bulk 
materials. It can be concluded from the white light interferometer maps that the machining of the nitrogen sprayed samples occurs as a result of failure of interparticle boundaries (in both as made and annealed state), while for helium sprayed samples the material removal can involve a combination of chip formation and interparticle boundary failure. Annealing of the helium sprayed material improves the ductility and strength of the interparticle boundaries, leading to purely chip formation being observed, and an improvement in the machined surface. To obtain good machinability it is necessary to ensure good interparticle bonding and low porosity. This will allow for the production of continuous chips and a smooth machined surface.

There is therefore evidence, demonstrated in this work, that the parameters used in Cold Spray processing will considerably affect the post-machining performance of samples.

\section{References}

1. Y. Cormier, P. Dupuis, B. Jodoin, and A. Corbeil, Mechanical Properties of Cold Gas DynamicSprayed Near-Net-Shaped Fin Arrays, J. Therm. Spray Technol., 2014, 24(3), p 476-488, doi:10.1007/s11666-014-0203-1.

2. A. Sova, S. Grigoriev, A. Okunkova, and I. Smurov, Potential of Cold Gas Dynamic Spray as Additive Manufacturing Technology, Int. J. Adv. Manuf. Technol., 2013, 69(9-12), p 2269-2278, doi:10.1007/s00170-013-5166-8.

3. V. Champagne, "The Cold Spray Materials Deposition Process: Fundamentals and Applications," Elsevier, 2007.

4. J.C. Lee, H.J. Kang, W.S. Chu, and S.H. Ahn, Repair of Damaged Mold Surface by Cold-Spray Method, CIRP Ann. - Manuf. Technol., Elsevier, 2007, 56(1), p 577-580.

5. C.A. Widener, M.J. Carter, O.C. Ozdemir, R.H. Hrabe, B. Hoiland, T.E. Stamey, V.K. Champagne, and T.J. Eden, Application of High-Pressure Cold Spray for an Internal Bore Repair of a Navy Valve Actuator, J. Therm. Spray Technol., Springer US, 2015, 25(1-2), p 193-201, doi:10.1007/s11666015-0366-4

6. R. Lupoi, C. Stenson, K.A. McDonnell, D.P. Dowling, and E. Ahearne, Antifouling Coatings Made with 
Cold Spray onto Polymers: Process Characterization, CIRP Ann. - Manuf. Technol., 2016, 65(1), p $545-548$.

7. J. Pattison, S. Celotto, R. Morgan, M. Bray, and W. O’Neill., Cold Gas Dynamic Manufacturing: A NonThermal Approach to Freeform Fabrication, Int. J. Mach. Tools Manuf., 2007, 47(3-4), p 627-634.

8. B. Aldwell, D. Trimble, S. Yin, and R. Lupoi, Enabling Diamond Deposition with Cold Spray through the Coated Particle Method, Mater. Sci. Forum, 2017, 879, p 1194-1199.

9. M. Bashirzadeh, F. Azarmi, C.P. Leither, and G. Karami, Investigation on Relationship between Mechanical Properties and Microstructural Characteristics of Metal Matrix Composites Fabricated by Cold Spraying Technique, Appl. Surf. Sci., Elsevier B.V., 2013, 275, p 208-216, doi:10.1016/j.apsusc.2012.12.166.

10. M.R. Rokni, C.A. Widener, O.C. Ozdemir, and G.A. Crawford, Microstructure and Mechanical Properties of Cold Sprayed $6061 \mathrm{Al}$ in As-Sprayed and Heat Treated Condition, Surf. Coatings Technol., Elsevier B.V., 2017, 309, p 641-650, doi:10.1016/j.surfcoat.2016.12.035.

11. R. Morgan, P. Fox, J. Pattison, C. Sutcliffe, and W. O’Neill, Analysis of Cold Gas Dynamically Sprayed Aluminium Deposits, Mater. Lett., 2004, 58(7-8), p 1317-1320.

12. M. Grujicic, C.L. Zhao, W.S. DeRosset, and D. Helfritch, Adiabatic Shear Instability Based Mechanism for Particles/substrate Bonding in the Cold-Gas Dynamic-Spray Process, Mater. Des., 2004, 25(8), p 681-688.

13. F. Klocke, "Manufacturing Processes 1," 2011.

14. G. Lu, G.Q. Lu, and Xiao Z.M., Mechanical Properties of Porous Materials, J. Porous Mater., 1999, 6, p 359-368.

15. M. Czampa, S. Markos, and T. Szalay, Improvement of Drilling Possibilities for Machining Powder Metallurgy Materials, Procedia CIRP, Elsevier B.V., 2013, 7, p 288-293, doi:10.1016/j.procir.2013.05.049.

16. O.R. Tutunea-Fatan, M. a. Fakhri, and E. V. Bordatchev, Porosity and Cutting Forces: From Macroscale to Microscale Machining Correlations, Proc. Inst. Mech. Eng. Part B J. Eng. Manuf., 2011, 
225(5), p 619-630, doi:10.1177/2041297510394057.

17. J. Schoop, M. Effgen, T.J. Balk, and I.S. Jawahir, "The Effects of Depth of Cut and Pre-Cooling on Surface Porosity in Cryogenic Machining of Porous Tungsten," Procedia CIRP, 2013, p 357-362.

18. M. Arft, F. Klocke, and D. Lung, Evaluation of the Machining Aspects of Austempered Ductile Iron, Int. J. Met., 2012, 6(4), p 35-42.

19. M. Abolghasemi Fakhri, E. V. Bordatchev, and O.R. Tutunea-Fatan, An Image-Based Methodology to Establish Correlations between Porosity and Cutting Force in Micromilling of Porous Titanium Foams, Int. J. Adv. Manuf. Technol., Springer-Verlag, 2012, 60(9-12), p 841-851, doi:10.1007/s00170-011-3647-1.

20. A. Bordin, A. Ghiotti, S. Bruschi, L. Facchini, and F. Bucciotti, Machinability Characteristics of Wrought and EBM CoCrMo Alloys, Procedia CIRP, Elsevier B.V., 2014, 14, p 89-94, doi:10.1016/j.procir.2014.03.082.

21. M.S.A. Aziz, T. Ueda, T. Furumoto, S. Abe, A. Hosokawa, and A. Yassin, Study on Machinability of Laser Sintered Materials Fabricated by Layered Manufacturing System: Influence of Different Hardness of Sintered Materials, Procedia CIRP, Elsevier, 2012, 4, p 79-83, doi:10.1016/j.procir.2012.10.015.

22. F. Montevecchi, N.N.N. Grossi, H. Takagi, A. Scippa, H. Sasahara, and G. Campatelli, Cutting Forces Analysis in Additive Manufactured AISI H13 Alloy, Procedia CIRP, Elsevier B.V., 2016, 46, p 476479.

23. E.A. Starke and J.T. Staley, Application of Modern Aluminum Alloys to Aircraft, Prog. Aerosp. Sci., 1996, 32(2-3), p 131-172, doi:10.1016/0376-0421(95)00004-6.

24. E. Louvis, P. Fox, and C.J. Sutcliffe, Selective Laser Melting of Aluminium Components, J. Mater. Process. Technol., Elsevier B.V., 2011, 211(2), p 275-284, doi:10.1016/j.jmatprotec.2010.09.019.

25. E.C. Santos, M. Shiomi, K. Osakada, and T. Laoui, Rapid Manufacturing of Metal Components by Laser Forming, Int. J. Mach. Tools Manuf., 2006, 46(12-13), p 1459-1468.

26. R.. C. Dorward and C. Bouvier, A Rationalization of Factors Affecting Strength, Ductility and 
Toughness of AA6061-Type Al-Mg-Si-(Cu) Alloys, Mater. Sci. Eng. A, 1998, 254(1-2), p 33-44, doi:10.1016/S0921-5093(98)00761-8.

27. A.T. Brammer, J.B. Jordon, P.G. Allison, and M.E. Barkey, Strain-Controlled Low-Cycle Fatigue Properties of Extruded 6061-T6 Aluminum Alloy, J. Mater. Eng. Perform., Springer US, 2013, 22(5), p 1348-1350, doi:10.1007/s11665-012-0411-0.

28. a. C. Hall, D.J. Cook, R. a. Neiser, T.J. Roemer, and D. a. Hirschfeld, The Effect of a Simple Annealing Heat Treatment on the Mechanical Properties of Cold-Sprayed Aluminum, J. Therm. Spray Technol., 2006, 15(2), p 233-238.

29. H.E. Chandler, “Heat Treater's Guide : Practices and Procedures for Nonferrous Alloys," ASM International, 1996.

30. G.E.P. Box, J.S. Hunter, and W.G. Hunter, "Statistics for Experimenters: Design, Innovation, and Discovery," Wiley Online Library, 2005.

31. Y. Bayat Asl, M. Meratian, A. Emamikhah, R. Mokhtari Homami, and A. Abbasi, Mechanical Properties and Machinability of 6061 Aluminum Alloy Produced by Equal-Channel Angular Pressing, Proc. Inst. Mech. Eng. Part B J. Eng. Manuf., 2015, 229(8), p 1302-1313, doi:10.1177/0954405414535921.

This is a post-peer-review, pre-copyedit version of an article published in The Journal of Thermal Spray Technology. The final authenticated version is available online at: https://doi.org/10.1007/s11666-017-0586-x 